\title{
Intertextos e mediações culturais em Nélida Pinõn
}

\author{
Carlos Magno Gomes*
}

\begin{abstract}
Resumo
Este artigo faz um estudo sobre as marcas pós-modernas do romance de autoria feminina no início do século XXI, com destaque para Vozes do deserto (2004), de Nélida Piñon. Por ser uma paródia de Mil e uma noites, essa obra traz referências ao processo narrativo, ao mesmo tempo em que descreve a luta de Scherezade por liberdade. Com tal empreitada, essa narradora explora a irreverência e a criatividade como armas contra a violência patriarcal. Metodologicamente, abordamos conceitos estéticos e culturais de paródia, metanarratividade e identidade, propostos por Eduardo Coutinho, Umberto Eco e Zygmunt Bauman.
\end{abstract}

Palavras-chave: Paródia. Intertextualidade. Metanarratividade.

Nos últimos anos do século $\mathrm{XX}$, as escritoras brasileiras incorporaram diferentes recursos estéticos que desintegraram as fronteiras narrativas do romance. Das experiências-limite de Clarice Lispector, em Um sopro de vida (1978), passando pela paródia da autobiografia de Lygia Fagundes Telles, em As horas nuas (1989), e pelo romance metaficcional de Lya Luft, O ponto cego (1999), temos três décadas de muitas experimentações estéticas e de quebras da narrativa tradicional. Essas escritoras exploram suas próprias experiências anteriores por meio de textos metanarrativos que se apropriam de aspectos culturais e estéticos para ressaltar a dinâmica artística da contemporaneidade.

Essa postura crítica de descentramento da narrativa tradicional também faz parte da forma como Nélida Piñon produz sua literatura, sobretudo, quando recepciona obras clássicas por meio de narrativas divertidas e irônicas. Ela brinca com textos canônicos para colocá-los à disposição de suas personagens femininas e feministas. Nesse caso, a marca da contemporaneidade de sua obra está vinculada à intertextualidade e à forma paródica como reescreve os clássicos universais. Com tal estratégia, assim como as escritoras citadas, Nélida Piñon se filia esteticamente ao romance pós-moderno, descentralizando as normas e os padrões artísticos anteriores.

* Universidade Federal de Sergipe. Pesquisador em estágio de pós-doutorado do Programa de PósGraduação em Antropologia Social da UnB. Bolsista CNPq. 
Para além dessa estética de revisão do passado, Nélida Piñon problematiza a voz da mulher artista em seus romances, dando espaço a personagens marginalizadas e excluídas, que se projetam de forma irreverente pelos espaços da tradição patriarcal. Essa abordagem paródica está presente em A força do destino (1978) e em A doce canção de Caetana (1987), obras que recriam os enredos das óperas do italiano Giuseppe Verdi por meio da quebra da fronteira entre o "texto escrito" e o "texto encenado", privilegiando as protagonistas transgressoras.

De forma mais contundente, Piñon retoma essa técnica narrativa em Vozes do deserto (2004), quando reescreve a clássica narrativa Mil e uma noites, do imaginário popular árabe, pelo prisma de uma escritora contemporânea. Alinhando uma revisão paródica à luta feminista, essa obra descreve a violência contra as mulheres, que eram sacrificadas após a primeira noite com o Califa. Tal tragédia era uma forma de vingança que esse soberano impôs às jovens do califado, após descobrir que fora traído pela esposa. Por ser metaficcional, essa obra trata da sua própria condição de arte, ao retomar o enredo da narrativa árabe, transportando Scherezade para as páginas de um romance atual.

Para este artigo, exploraremos a revisão paródica como uma técnica pósmoderna, presente em Vozes do deserto, que sintetiza uma das principais formas estéticas do romance de autoria feminina do final do século XX, no Brasil. No primeiro momento, vamos eleger algumas características da narrativa pósmoderna, conforme as abordagens de Umberto Eco (2003) e Eduardo Coutinho (2005) e, no segundo, analisaremos como tais peculiaridades se manifestam no texto de Piñon. Na sequência, enumeramos alguns aspectos das narrativas pósmodernas, com destaque para a dualidade do texto paródico: que fala de si por meio da metanarratividade, enquanto deixa pistas do deslocamento das identidades em jogo.

\section{Marcas da narrativa pós-moderna}

$\mathrm{Na}$ literatura pós-moderna, temos diversas instâncias narrativas sendo questionadas, por meio da fragmentação da identidade do narrador, do texto $\mathrm{e}$ até do leitor. A instabilidade passa a fazer parte do próprio estatuto da literatura contemporânea. Essa forma de representação questiona os limites do texto literário, pois a arte pós-moderna privilegia, entre outros recursos, a metanarratividade, a polifonia de vozes, a consciência hiperbólica e o caráter paródico da arte 
(COUTINHO, 2005, 171-172). Tais marcas fazem parte de diversas obras, que desafiam seu próprio estatuto ao eleger a experimentação de novas linguagens como uma prática do fazer artístico. (VATTIMO, 2002).

Outra marca do texto pós-moderno está na sua postura de abrir espaço para a voz do outro. Assim, metanarratividade e alteridade podem ser consideradas duas marcas da arte pós-moderna. Combinadas de forma equilibrada, esses dois recursos têm se repetido na produção literária do início do século XXI. O duplo movimento desse tipo de arte pode ser justificado pelo fato de que o texto está sendo narrado como parte da busca da voz do outro, isto é, como uma poética da alteridade que se articula em torno da possibilidade de o autor se reconhecer no outro. (OLIVIERI-GODET, 2007, p. 237).

No caso da literatura brasileira, identificamos um compromisso com a voz da mulher, em contexto de violência de gênero, em diversos romances produzidos nas últimas décadas. Por exemplo, Conceição Evaristo, em Ponciá Vicêncio (2003), dá voz a uma empregada doméstica negra que resgata a memória rural de seus ancestrais como uma saída da violência social que sofre na cidade. Já, Nélida Piñon, em Vozes do deserto (2004), retoma o tema do feminicídio como uma ameaça às mulheres, ao construir uma protagonista que procura salvar as mulheres da morte imposta por uma questão de honra masculina do Califa.

Nesses dois casos, o jogo metanarrativo dá o tom a esses romances preocupados menos com estratégias estilísticas do que com mecanismos que exponham a voz da mulher em situação de conflito. Com isso, ao mesmo tempo em que fala de si, esse tipo de narrativa busca soluções sociais para os conflitos narrados, quando explora o tom irônico de seus questionamentos. Assim como os romances de Clarice Lispector, Lygia Fagundes Telles e Lya Luft, citados anteriormente, as obras de Conceição Evaristo e Nélida Piñon têm, em particularidade, o engajamento com a luta das mulheres pelo direito à liberdade.

Além disso, os textos de autoria feminina do início do século XXI incorporam a repetição de temas como uma estratégia de revisão, uma prática não inocente. No caso do texto de Nélida Piñon, tal recurso fica mais visível, por se tratar de paródias anunciadas, que carregam a intencionalidade, que tanto pode dar continuidade, quanto ser subversiva (CARVALHAL, 2010, p. 54). Nesse romance, a subversão é exposta nas estratégias feministas usadas pela protagonista para libertar as mulheres da punição do Califa. 
Tal interpretação é possível quando incluímos a série cultural como parte dos intertextos que uma obra carrega, já que a intertextualidade nos convida também a expandir o estudo da relação entre texto e história, valorizando aspectos ideológicos que os arquivos literários registram, seja "aleatória ou consentida, uma vaga lembrança, ou mesmo homenagem explícita, ou, ainda, submissão a um modelo, subversão do cânone ou inspiração voluntária" (SAMOYAULT, 2008, p. 10). O texto contemporâneo tende a subverter o texto canônico.

Quando nos referimos à paródia, pensamos também no processo da intertextualidade da diferença conforme a proposta de Afonso Romano de Sant'Anna de reconhecer diferentes níveis de intertextualidade: paráfrase, estilização e paródia (SANT'ANNA, 2007, p. 20). No caso de uma intertextualidade paródica, o texto recepcionado pode ser visto como "um filho rebelde, que quer negar sua paternidade e quer autonomia e maioridade". (SANT'ANNA, 2007, p. 32).

Dentro de tal perspectiva, o processo de construção de um texto leva em conta a importância dos intertextos como partes da memória da literatura. Assim, a intertextualidade pode ser vista como "uma poética inseparável de uma hermenêutica: trata-se de ver e de compreender do que ela procede, sem separar esse aspecto das modalidades concretas de sua inscrição" (SAMOYAULT, 2008, p. 47). O texto contemporâneo pós-moderno tende a brincar com tais referências e nos convida a ficarmos atentos ao jogo de referências condensadas na tessitura literária.

$\mathrm{Na}$ esteira desse debate, trazemos para a cena o próprio conceito de texto e de literatura, visto que, na arte pós-moderna em geral, a perspectiva paródica faz-se inquietante por trás das questões culturais. Como destacado pelas feministas, no texto de autoria feminina, o uso da paródia faz parte de uma estratégia que trata menos de arte e mais de opressão da mulher, pois esse jogo estético da repetição é explorado a serviço de um caráter revisionista. (CAMPELLO, 2006).

Ao tratar dos excluídos, o romance pós-moderno tenta fragmentar conceitos hegemônicos, por meio de um discurso que privilegia a diferença como um referencial de interpretação. Nesse contexto, investigamos como a cultura da diferença questiona a padronização, e como o particular anuncia seu lugar de fala. Nesse sentido, podemos dizer que a produção feminina do início do século XXI incorpora uma das propostas da identidade pós-moderna ao destacar "as reivindicações do particular contra a pressão homogeneizante do geral". (BAUMAN, 2007, p. 73). 
$\mathrm{Na}$ narrativa brasileira, especificamente, o lugar de fala da escritora é questionado por meio da intromissão autoral e da metanarratividade presentes nos textos de diversas escritoras, sejam as canônicas, Clarice Lispector, Lygia Fagundes Telles, Lya Luft, Nélida Piñon, Marina Colasanti, sejam as menos conhecidas, como Conceição Evaristo, Helena Parente Cunha, Patrícia Melo, entre outras. Isso acontece de forma direta ou indireta quando o texto reproduz a fragmentação do estatuto artístico por meio da "ironização dos gêneros literários", ou da "reescrita", ou da "poética da citação". (VATTIMO, 2002, p. 42).

Neste trabalho, destacamos a "poética da citação" como um movimento, que fragmenta o conceito de texto e de representação, pois o texto dá destaque à memória dos textos lidos por seu autor. Vale ressaltar que essa estratégia é atravessada pela repetição, como estratégia de escrita, já que, como parte de discursos passados, um texto atual pode tomar forma e relevância (ECO, 2003, p. 198). Reconhecendo esse processo de criação e interpretação, a intertextualidade pode ser explorada como um parâmetro criativo das obras do início do século XXI, pois explicita o olhar paródico do passado.

A obra pós-moderna, que é atravessada por outros textos, pede um leitor atento à coleção de referências que carrega. Esse leitor deve ir além do jogo metanarrativo para se infiltrar no jogo estético, proposto na partitura da narrativa, para recepcionar criticamente esses retalhos de obras anteriores. Umberto Eco nos ensina que o "leitor modelo" é o ideal para o reconhecimento desses movimentos estéticos, que uma obra traz em si (ECO, 2003, p. 199).

Outra marca do texto contemporâneo pode ser identificada na tendência da fragmentação identitária de suas personagens. Assim, o texto problematiza a construção das identidades marginalizadas sem lhes impor um formato, um padrão, pois essas personagens estão sempre em movimento e em busca de outros espaços, reconhecendo que "há diferenças a serem atenuadas ou desculpadas ou, pelo contrário, ressaltadas e tornadas mais claras” (BAUMAN, 2005, p. 19). Esse conflito é próprio das paródias feministas que revisam o passado sem pregar uma saída engessada para a mulher do presente.

A seguir, analisaremos alguns aspectos dessa narrativa contemporânea na ficção de Nélida Piñon. Vamos investigar quais as principais marcas pós-modernas do romance Vozes do deserto, com destaque para seu lugar de revisão crítica do passado e para o final aberto, como uma possibilidade de negociação para as identidades femininas em trânsito. 


\section{A performance da narradora}

Vozes do deserto é reconhecidamente uma obra literária paródica ao propor a revisão do passado por meio da reescrita do imaginário árabe por um prisma feminista contemporâneo, pois privilegia a focalização da contadora de histórias de Mil e uma noites, Scherezade. Na versão de Piñon, essa jovem também se doa ao sacrifício, na tentativa de salvar as virgens da morte, mas tem um plano secreto e particular de seduzir o Califa por meio de suas narrativas.

Portanto, a protagonista é uma grande narradora, uma artista que busca a salvação das mulheres do califado por meio de seu poder de contar histórias. Ela aprendera essa técnica com "Fátima, a ama que, após a morte prematura da mãe, ensinara-lhe a contar histórias" (PIÑON, 2004, p. 8). Scherezade parte em busca de uma saída para os crimes cometidos pelo Califa contra suas esposas. Essa jovem trazia esperança para todos: "em torno da jovem floresciam sentimentos na iminência de desembocar em um desfecho trágico". (PIÑON, 2004, p. 9).

Sem temer o destino, Scherezade procura adiar o sacrifício a cada aurora ao deixar uma história em suspense. Todavia corre o risco de ser punida com sua própria vida, visto que seu plano "poderia facilmente escapar ao seu controle" (PIÑON, 2004, p. 9). Nesse contexto de terror, o perigo da morte está associado ao suspiro por mais um dia de vida. Contar histórias era sua saída em busca de dias melhores; a salvação das mulheres do reino estava condicionada a sua criatividade. Ela buscava vencer o tempo da vingança e dos crimes contra jovens indefesas que foram amaldiçoadas por um Califa traído: "Por ordem do soberano, nenhum sangue vil, criminoso e traidor, além de jovens, mancharia o piso de mármore diariamente preparado para a cerimônia de execução das esposas". (PIÑON, 2004, p. 11).

Com o ímpeto de livrar as mulheres de tal ritual de assassinato, Scherezade escavava o imaginário para seduzir o Califa: "suas histórias, semeadas de atitudes heroicas e imprudentes, saciam os ouvintes famintos, mantendo o interesse do Califa até o amanhecer" (PIÑON, 2004, p. 35). A arte de contar era a única arma que tinha para sobreviver àquele castigo misógino imposto pelo Califa. Cada dia um novo desafio, cada dia ela usava uma estratégia mais sedutora para despertar o prazer do ouvinte, que, atraído pelo desfecho da história suspensa, dava-lhe mais um dia de vida. 
Assim, na obra de Nélida Piñon, como em Mil e uma noites, narrar significa buscar um caminho para a salvação da mulher. A violência é um fantasma que ronda o palácio e o reino. A ideia de opressão é reforçada pela questão temporal, visto que, todos os dias, a narradora estava jurada de morte por ser uma mulher jovem e ter se casado com o Califa. Tal espaço-tempo é sombrio e assustador e contrasta com o poder de criação da jovem narradora. Com essa ameaça contínua, o assédio moral é pavoroso, por isso as mulheres envolvidas na trama estão unidas em busca de reverter esse clima de terror: "Reunidas nos aposentos, Scherezade mal dissimula a náusea. O medo que sente lhe acentua o desconforto provindo do convívio forçado com as escravas em torno". (PIÑON, 2004, p. 12).

A arte de narrar é também de se salvar, pois, sem suas histórias, Scherezade estaria condenada ao cadafalso. Essa aproximação do "eu" da narrativa com as causas da mulher aponta outra particularidade dessa obra, que nos remete a uma metanarratividade crítica, uma vez que "a projeção do eu da artista e do mundo estabelecem relações de similitude entre essa projeção e outros tipos de representação, extra e intradiegéticos, o que resulta em uma cadeia, em abismo, de significações (myse-en-abyme)" (CAMPELLO, 2006, p. 129).

Nesse sentido, vale lembrar que, tradicionalmente, o romance pós-moderno explora a metanarratividade por uma via dupla: fala do próprio ato de narrar; e destaca o lugar descentrado da identidade que se reconstrói por meio do texto que está sendo contado. Essa dupla preocupação perpassa a obra de Piñon, reforçando o prisma paródico que ele assume desde as primeiras linhas da obra: "Uma turbulência, graças à qual ia tocando o coração da arte de inventar, enquanto renunciava à própria alma em troca das demais”. (PIÑON, 2004, p. 248).

Essa relação da narrativa com a salvação da protagonista nos traz uma metáfora do quando a literatura/arte pode vencer a violência masculina. Nesse contexto adverso, a criatividade e a união das mulheres eram usadas como estratégias de resistência: "Sem ele perceber que a meta da jovem era jamais deixar os fios soltos do relato no ar, de modo a poder atá-los na noite seguinte" (PIÑON, 2004, p. 27). Como parte da ficção preocupada em discutir seus próprios limites, observamos que esse romance valoriza a performance artística por meio do processo paródico e de autorreflexão textual (COUTINHO, 2005, p. 170-1). Dessa forma, o romance explora o ritmo paródico à medida que narra a história de uma artista que tem consciência de que ela também exerce uma relação de poder no meio daquele conflito. 
No processo metanarrativo, suas táticas de contar vão the dando sobrevida e outras possibilidades de narrar: "cedia-lhe, involuntariamente, a máquina de fabricar sonhos, admitia de público que qualquer história, pronunciada com língua solene, salva a quem seja da visão do cadafalso" (PIÑON, 2004, p. 28). Como a alternância do jogo metanarrativo, essa obra também brinca com o próprio conceito de texto paródico, pois traz uma reflexão sobre a forma como está sendo narrado em relação ao texto anterior. (ECO, 2003, p. 218).

Além da luta pelo direito da mulher, a intertextualidade com a narrativa árabe é tomada de diferentes formas: seja na retomada da história trágica da protagonista, seja pela forma como as personagens desse clássico ganham forma na versão brasileira: "São muitos os personagens que navegam pelo interior de sua nau. Sem dúvida, Simbad, agora de volta, é dos mais persistentes" (PIÑON, 2004, p. 51). Nesse jogo narrativo de Scherezade, identificamos a poética da citação que abre o texto para os murmúrios de outros tantos, reforçando sua condição pós-moderna, na qual "o supra-sentido intertextual é horizontal, labiríntico, rizomático e infinito de texto em texto - não havendo outra promessa senão o murmúrio contínuo da intertextualidade". (ECO, 2003, p. 218).

Com o terror da noite acabando, a jovem narradora toma cuidado com suas infinitas histórias: "Quase perdida, agarra-se às metáforas que lhe vêm ao encalço" (PIÑON, 2004, p. 53). Nesse sentido, ao intercalar a trajetória da protagonista com referências ao próprio ato de narrar, essa obra ressalta o quanto as conexões do texto narrado com os textos antecedentes são indispensáveis para uma leitura atualizada, visto que "se no texto aparece uma possível citação, e esta citação parece conjugar-se com o resto do texto (e de suas outras citações), os propósitos do autor empírico contam pouco". (ECO, 2003, p. 215).

Narrativa e persuasão andam juntas nessa obra. A sedução por sua capacidade de fabular, aos poucos vai ganhando espaço nas noites do soberano: "para que não decresça o interesse do Califa, implanta no enigmático homem um vício que o impede de libertar-se da volúpia de ouvir seus contos" (PIÑON, 2004, p. 214). Ao falar da volúpia do texto narrado, a obra retoma o mosaico de intertextos com o qual é composta, convidando o leitor a saborear "os perfumes de outros textos que precedem aquela tradição". (ECO, 2003, p. 218).

Além disso, ao retomar a narrativa árabe, esse romance, visto como paródia, não busca apenas repetir o enredo original, mas destacar o lugar da mulher no contexto patriarcal. Essa visão paródica se justifica por funcionar, esteticamente, 
como um contraestilo, que desloca as coisas do lugar comum (SANT'ANNA, 2007 , p. 29). Seguindo essa pista, temos um romance metaficcional que apresenta um ruído do texto recepcionado, dando pistas de sua proposta de problematizar a narrativa anterior. Tal forma é um dos traços da arte pós-moderna, marcada pela autorreflexão crítica, visto que "seu êxito consiste, antes, fundamentalmente, em tornar problemático esse âmbito, ultrapassando, pelo menos momentaneamente, seus limites". (VATTIMO, 2002, p. 42).

\section{A identidade artística como resistência}

Neste tópico, destacaremos a relação da narradora com a reflexão sobre a identidade feminina. Esse processo identitário é inerente ao narrativo e atravessa toda a obra: "Mas enquanto Scherezade ia narrando os infortúnios dos personagens, as palavras da verdade ficcional a fortaleciam. Igual a Polixena, brotava-lhe do peito um grito que, diante da adaga na garganta, ameaçava jamais se extinguir" (PIÑON, 2004, p. 278). A relação da protagonista com a luta pela liberdade da mulher é contínua. Ela não abre mão de se sacrificar pelas outras jovens.

Tal sacrifício de uma protagonista, artista, fortalece a perspectiva feminista dessa obra, que nos convida a uma reflexão acerca das preocupações ideológicas dos textos de autoria feminina. Esse tipo de narrativa "direta ou indiretamente vincula-se à arte, à moral, à ética e à ideologia" (CAMPELLO, 2006, p. 129). Portanto, é nesse sentido que o romance traz rastros do estilo pós-moderno ao ser metaficcional e ideologicamente marcado pela luta da liberdade feminina.

Na narrativa de Piñon, o lugar privilegiado da imaginação é apontado como uma estratégia de resistência da mulher. Ao narrar, ela adia o presente e valoriza o passado. Tal processo de construção identitária é próprio das personagens que optam por fazer parte de fronteiras e assumem a inconstância como uma marca de seus deslocamentos (LOURO, 2008, p. 21). A partir de estratégias secretas para sedução do Califa, podemos observar que Scherezade apresenta uma identidade feminina "provisória", pois está negociando novos espaços para si. (BAUMAN, 2005, p. 22).

O processo de construção da identidade da protagonista também é híbrido, pois à medida que consegue se defender e adiar sua morte, ela vai se fortalecendo e se projetando fora daquela prisão. Nesse sentido, podemos classificar Scherezade como uma personagem em trânsito que recusa a limitação das fronteiras corporais, 
ao assumir a "inconstância, a transição e a posição 'entre' identidades como intensificadoras do desejo" (LOURO, 2008, p. 22). Mesmo diante de normas rígidas, ela opta por comportamentos avessos ao padrão imposto, mostrando-se insatisfeita com a vida no califado.

Scherezade não se identifica com a vida sexual imposta pelo Califa. $\mathrm{O}$ ato sexual se restringe a um castigo. Como solução para o ato imposto, a escrava e a irmã passam a substituí-la, seja nas tarefas sexuais, seja na arte de contar histórias: "Dinazarda serviria ao Califa na cama, enquanto Jasmine, recém-descobrindo a tardia vocação de contadora, iria entreter o soberano com histórias que há muito tinha no caldeirão da bruxa, como considerava sua memória". (PIÑON, 2004, p. 347).

No jogo de adiamento da morte da contadora de história, o Califa é seduzido por suas habilidades e é traído pelo prazer de ouvi-la, mesmo sabendo que ela estava sendo substituída na cama: "estar ele disposto a viver em regime de farsa em troca das compensações habituais, constituídas dos relatos de Scherezade" (PIÑON, 2004, p. 332). A farsa se mantém pela imaginação de uma mulher inteligente e criativa: "Ultimamente o Califa vinha se perguntando se não chegara o momento de tentar viver sem Scherezade" (PIÑON, 2004, p. 340). Tal reconhecimento sugere que a voz da narradora é ouvida e o castigo foi vencido, chegando a hora do fim dos feminicídios do califado.

Insatisfeita com o ambiente do palácio e com a sexualidade imposta pelo Califa, a narradora planeja abandonar seu posto: "Chegara, pois, o momento de Scherezade partir. De seguir viagem, obedecendo às instruções de seu recalcado desejo" (PIÑON, 2004, p. 343). Essa opção reforça o quanto sua identidade é transitória e parte em busca de outro espaço todo seu, uma heterotopia. Para Michel Foucault, as heterotopias são "outros posicionamentos reais" para onde as identidades insatisfeitas se dirigem, pois são "espécies de lugares que estão fora de todos os lugares, embora eles sejam efetivamente localizáveis". (FOUCAULT, 2009, p. 415).

Ela passa a se projetar em duplo movimento, para fora do califado, ao mesmo tempo em que se projeta para dentro de si. Essa viagem-refúgio tem também um duplo sentido nessa obra, pois desqualifica o local da violência, enquanto delineia um território de resistência. Nesse processo, o deslocamento entre espaços reais e heterotópicos não é simples, pois "não há um lugar de chegar, não há um destino pré-fixado, o que interessa é o movimento e as mudanças que se dão ao longo do trajeto". (LOURO, 2008, p. 13). 
A projeção de Scherezade fora dos espaços do palácio reforça a estrutura pós-moderna desse romance, que privilegia o deslocamento identitário feminino. Ao contextualizar um clássico que não dava espaço para a mulher, Nélida Piñon propõe uma saída irreverente para sua protagonista que abandona o espaço dos castigos patriarcais. Com tal final, o romance reforça a fragmentação identitária, ao apresentar diferentes caminhos para suas personagens femininas, pois, como já se viu, "há diferenças a serem atenuadas ou desculpadas ou, pelo contrário, ressaltadas e tornadas mais claras". (BAUMAN, 2005, p. 19).

Apesar da trágica história de feminicídio que perdura durante quase toda a trajetória da protagonista, a narrativa de Piñon projeta o corpo feminino fora daquela prisão, ao propor o final de liberdade da protagonista, que "cruzaria o deserto distraindo-se com os animais, em especial os camelos" (PIÑON, 2004, p. 347), com a finalidade de reencontrar sua ama, Fátima, "que a recebera de braços abertos tão logo chegou à casa, poeirenta, faminta, mas feliz" (PIÑON, 2004, p. 351). Depois de longas noites de narrativas, Scherezade alcança sua liberdade.

Para Elódia Xavier, essa perspectiva artística representada na ficção pode ser identificada como a representação do "corpo liberado", visto que a mulher abandona o sistema disciplinador para viver em plena liberdade (XAVIER, 2007, p. 176). Portanto, esse outro espaço heterotópico, fora do califado, é uma marca contemporânea dessa obra que abre espaço para o corpo liberado da protagonista que busca sua plenitude pessoal longe das amarras do palácio do Califa.

Portanto, a contextualização da luta da mulher por seus direitos fortalece o caráter revisionista desse romance, visto que a opressão do passado é lida por uma escritora contemporânea, que expõe um prisma feminista de um clássico quando propõe um final aberto para sua protagonista. Tal polifonia de vozes nos remete a “contextos transnacionais" - um espaço de valores e interesses comunitários - já que a escrita está interseccionada com as preocupações feministas e projeta um sujeito feminista transnacional. (CAMPELLO, 2006, p. 132).

\section{Considerações finais}

Ao aproximarmos Vozes do deserto das principais narrativas de autoria feminina do final do século passado, observamos que o texto de Nélida Piñon apresenta uma síntese desse período ao destacar a revisão crítica do mundo patriarcal. Por partir de um texto anterior, esse romance pode ser visto como 
uma obra que reforça a irreverência paródica. Tal modelo ganha o ajuste do olhar feminista que desconstrói o universo misógino do patriarcado, próprio das narrativas árabes.

Além da afinidade com as obras de Clarice Lispector, Lygia Fagundes Telles e Lya Luft, ressaltamos o diálogo que Vozes do deserto mantém com a irreverência feminista de Marina Colasanti, presente em suas narrativas para crianças e adultos, como em Doze reis e a moça no labirinto do vento (1978) e em Contos de amor rasgados (1986), respectivamente. Portanto, a obra de Nélida Piñon apresenta uma síntese das principais técnicas narrativas das últimas décadas do século anterior: metanarratividade, paródia, humor e irreverência, como recursos estéticos; e fragmentação identitária e resistência feminista, como recursos culturais.

Dentro da tradição dos estudos intertextuais, destacamos o quanto Nélida Piñon reescreve a obra do imaginário árabe pelo prisma feminista e contemporâneo, ao abrir o debate sobre o feminicídio em contextos patriarcais. Tal peculiaridade reforça o processo de recepção criativa do livro da brasileira que ilumina a obra anterior com uma abordagem irônica e atual, própria dos textos recepcionados de forma original (CARVALHAL, 2010, p. 70). Como uma obra pós-moderna, o romance de Piñon reforça seu duplo lugar de fala: descreve o próprio projeto metanarrativo ao mesmo tempo em que valoriza a voz da mulher oprimida. Esse tipo de ficção "inscreve a diferença nas suas escolhas formais, transformando o escritor em personagem, multiplicando os níveis narrativos e os pontos de vista". (OLIVIERI-GODET, 2007, p. 234).

Tal processo é original e aponta uma perspectiva de ampliação dos espaços de intersecção entre as obras do passado e do presente, reforçando o quanto a intertextualidade é um processo enriquecedor das obras contemporâneas. Por fim, destacamos o diferencial desse processo metanarrativo, quando explora a intertextualidade crítica a favor de construção de um novo ângulo do texto narrado: o prisma feminista que repudia a opressão e a violência de gênero. Isso foi possível porque o texto de Nélida Piñon ressalta conexões culturais e estéticas, que dinamizam o processo de recepção da obra anterior, "destemporalizando" esse texto que passa a ser usado como parte da contemporaneidade. (SAMOYAULT, 2008, p. 95). 


\title{
Intertexts and cultural mediations in Nélida Piñon
}

\begin{abstract}
This article is a study about the post-modern marks of the novel of feminine authorship in the beginning of XXI Century, especially Vozes do deserto (2004), by Nélida Piñon. As a parody of The thousand and one nights, the novel brings references to the narrative process while describing the fight of Scherezade for freedom. With this contract, that narrator explores the irreverence and creativity as weapons against the patriarchal violence. Methodologically, we explore aesthetic and cultural concepts of parody, metanarrativity and identity proposed by Eduardo Coutinho, Umberto Eco and Zygmunt Bauman.
\end{abstract}

Keywords: Parody. Intertextuality. Metanarrativity.

\section{Referências}

BAUMAN, Zygmunt. Identidade. Entrevista a Benedetto Vecchi. Tradução Carlos A. Medeiros. Rio de Janeiro: Jorge Zahar, 2005.

BAUMAN, Zygmunt. Vida líquida. Tradução Carlos A. Medeiros. Rio de Janeiro: Jorge Zahar, 2007.

COLASANTI, Marina. Contos de amor rasgados. 3. edição. Rio de Janeiro: Record, 2010.

COLASANTI, Marina. Doze reis e a moça no labirinto do vento. 12. ed. São Paulo: Global, 2006.

CAMPELLO, Eliane T. A. O Künstlerroman de autoria feminina no Brasil. In: CAVALCANTI, Ildney et al. (Org.). Da mulher às mulheres: dialogando sobre literatura, gênero e identidades. Maceió: Edufal, 2006. p. 125-133.

CARVALHAL, Tania Franco. Literatura Comparada. 5. ed. São Paulo: Ática, 2010.

COUTINHO, Eduardo, F. Revisitando o pós-moderno. In: GUINSBURG; J.; BARBOSA, Ana Mae (Org.). O pós-modernismo. São Paulo: Perspectiva, 2005. p. $159-172$.

ECO, Umberto. Ironia intertextual e níveis de leitura. In: ECO, Umberto. Sobre literatura. 2. ed. Tradução de Eliana Aguiar. Rio de Janeiro: Record, 2003. p. 199-218. 
EVARISTO, Conceição. Ponciá Vicêncio. Belo Horizonte: Mazza, 2003.

FOUCAULT, Michel. Outros espaços (Conferência). In: FOUCAULT, Michel.

Estética: literatura e pintura, música e cinema. Organização de Manoel Barros da Motta. Tradução de Inês Autran Dourado Barbosa, 2. ed. Rio de Janeiro: Fonte Universitária, 2009. p. 411-422.

GOMES, Carlos Magno. A alteridade no romance pós-moderno. São Cristóvão: Editora da UFS, 2010.

LISPECTOR. Clarice. Um sopro de vida. Rio de Janeiro: Rocco, 1999.

LOURO, Guacira Lopes. Um corpo estranho. Belo Horizonte: Autêntica, 2008.

LUFT, Lya. O ponto cego. São Paulo: Mandarim, 1999.

OLIVIERI-GODET, Rita. Estranhos estrangeiros: poética da alteridade na narrativa contemporânea brasileira. Estudos de literatura brasileira contemporânea. Brasília, n. 29, p. 233-252, jan./jun. de 2007.

PIÑON, Nélida. A doce canção de Caetana. Rio de Janeiro: Record, 1997.

PIÑON, Nélida. A força do destino. 2. ed. Rio de Janeiro: Record, 2005.

PIÑON, Nélida. Vozes do deserto. 2. ed. Rio de Janeiro: Record, 2004.

SAMOYAULT, Tiphaine. A intertextualidade: memória da literatura. Tradução de Sandra Nitrini. São Paulo: Hucitec, 2008.

SANT'ANNA, Affonso Romano de. Paródia, paráfrase \& cia. São Paulo: Ática, 2007.

TELLES, Lygia Fagundes. As horas nuas. São Paulo: Companhia das Letras, 2010.

VATTIMO, Gianni. O fim da modernidade. Tradução de Eduardo Brandão. São Paulo: Martins Fontes, 2002.

XAVIER, Elódia. Que corpo é esse? O corpo no imaginário feminino. Santa Catarina: Mulheres, 2007.

Recebido em 30/04/2016.

Aceito em 29/09/2016. 